\title{
Who "owns" the network?: a case study of new media artists' use of high-bandwidth networks
}

\author{
Frédérik Lesage ${ }^{1}$ \\ Department of Media and Communications \\ London School of Economics and Political Sciences \\ Houghton Street \\ London WC2A $2 A E$ \\ United Kingdom \\ E-mail:f.lesage@lse.ac.uk
}

The objective of this paper is to briefly give an overview of a research project dealing with the social construction of use of information communication technologies among new media artists interested in online collaboration. It will outline the theoretical and methodological tools applied to the case study of the MARCEL Network.

Lighting the Blue Touchpaper for UK e-Science - Closing Conference of ESLEA Project The George Hotel, Edinburgh, UK

26-28 March, 2007

\footnotetext{
1 Speaker
} 


\section{Introduction}

Near the end of his classic work on the social construction of art and the coordination of artistic activity, Howard S. Becker (1982, pp.314-350) details a fascinating comparison between the development of two similar technologies with somewhat promising artistic applications in the late $19^{\text {th }}$ and early $20^{\text {th }}$ century. The first of these technologies is the stereoscope, the second is the photograph. In his account, he describes how the latter went on to be accepted by most of society from the amateur to international high art institutions as a tool for artistic creation while the former became a temporary fad that was quickly relegated to obscure collections of curiosities. Although Becker is unable to give the reader a definitive answer as to why one succeeded while the other did not, it is fascinating to extend his reflections to new media technologies and to ask how some of these may one day contribute to the work of a contemporary Stieglitz. One approach could involve documenting how these digital technologies are currently employed by artists. This way, it may be possible to contribute to a wider understanding of the dialogical relationships between artists, the tools they use, and the wider art world that surrounds them.

With this is mind, a case study has been put together to observe how artists apply the network metaphor to information and communication technologies (ICTs), specifically highbandwidth academic networks, in order to coordinate the collaborative online production of new media artworks. The two main research questions are:

How does the network metaphor enable media artists to coordinate the online collaborative production of art works?

How does it enable the coordination of consumption/use of ICTs?

This paper will briefly set out the theoretical and methodological framework guiding this case study as well as provide some observations stemming from preliminary fieldwork. It will then attempt to demonstrate how the research structure and its findings might benefit those working in the field of e-science.

\section{Theoretical framework}

Research in the social sciences pertaining to artists often focuses on their role as producers. The production of culture perspective (Peterson \& Anand 2004), for example, applies organisational sociology to the study of how producers and distributors organise in order to better understand the dynamics of power that structure the meanings of cultural products before they eventually make it to the general public. But where the paint of a painting comes from is rarely of interest to the viewer. Some, such as those in the field of audience studies (Livingston 1998), would argue that the viewers themselves can generate all sorts of meanings independently of the producers intentions. But in the case of this research, the relationship between the artists, their support personnel and the new media technologies remains unstable. 
The research must focus instead on the "dynamics of uses" (Martin-Barbero 1993), the shifts between strategies and tactics (de Certeau 1984) and between the role of producer and consumer among actors and organisations that are trying to acquire or maintain creative power. We are observing what some in the $19^{\text {th }}$ or $20^{\text {th }}$ century might have called an "avant-garde movement" where experimentation with conventions is taking place. But these days it is called a "network" of "project managers" and "web developers". In order to this, the research calls on a theoretical framework that combines the model of conventions as developed by Becker (1982) with MartinBarbero's (1993) model of mediation in order to allow the researcher to follow the articulations between institutional traditions (such as the contemporary art world, new media, and academia), the actors that maintain these traditions, and the technologies that support their activities.

Employing Lammers and Barbour's (2006) model of institutions it will be possible to identify institutional discourses and practices relating to the art world and to new media and to see how they are reproduced by individual actors and organisations in order to mediate the conventions pertaining to the use and production of ICTs. This may in turn provide a glimpse into the ways ICTs are selected and used by individual artists and arts organisations. It may also provide us with the tools to observe whether institutional power relations enable the social construction of the new media artist as an empowered actor in the field of new media.

\section{Research design and methodology}

The case study selected for the research is the MARCEL Network. It is first conceived during a series of conferences in the late-1990s in Souillac (Foresta \& Barton 1998). Following this, a number of artists and other new media art practitioners set out to build "a permanent broadband interactive network and web site dedicated to artistic, educational and cultural experimentation, exchange between art and science and collaboration between art and industry" (MARCEL 2004). By 2001 experimentations with high-speed academic networks between Le Fresnoy (France), the Wimbledon School of Art (UK), and Ryerson (Canada) are attempted. The Public in West Bromwich and other new media centres and academic institutions across Europe and North-America (Ibid) soon follow suit. Most of the experimentations centre on the realtime collaborative potential of video-teleconferencing software such as Access Grid.

The research design consists of a multi-sited ethnographic case study (Marcus 1998) of the MARCEL Network's activities. The researcher will follow the network's activities over a two and a half year period, visiting locations across Europe and North America with the objective of generating:

1) Multiple "career threads" through document analysis and interviews. It is hoped that, by not only documenting the careers of individual artists (Peterson 2004) but also documenting the careers of the technologies used (Kopytoff 1986, Silverstone et al. 1991) and the organisation as a whole, it will be possible to produce a sufficiently clear historical context for the Network's activities. 
2) Field notes and audio recordings of participant observation of Networks activities as well as interviews of key actors for ethnographic and discourse analysis.

These two empirical objectives respectively constitute a moment of socio-historical analysis and a moment of formal analysis which will then be combined in a moment of interpretation-reinterpretation (Phillips and Brown 1993) as part of a complete critical hermeneutic methodology. Using this approach allows the researcher to attempt to triangulate the observations in order to distinguish particular conventions as well as go further into an analysis of how these conventions are mediated when communicated between different actors or organisations in the field. The principal research objective is to come to a critical analytical understanding of artists' application of the network metaphor to ICTs in order to coordinate the production and use of new media artworks. Although it will be impossible to reach a definitive objective conclusion, it is hoped that such an imprecise description can eventually lead to a better shared understanding of creative activity in new media.

\section{Preliminary findings}

The case study has passed its mid-point phase. Although there remains much work to be done before presenting any compelling findings, it is possible to present a few preliminary observations and hypotheses. Most new media artists encountered over the course of the research seem to face considerable challenges due to limited resources, both in terms of financial and institutional support. Although the word "network" is somewhat inconsistently applied by actors, it does seem to preserve a certain particular characteristic across most of the organisation's members which allow them to deal with this limited support. The characteristic can be summarized as an implicit understanding of the importance of disseminating and maintaining particular kinds of "ownership" (Strathern 1996) of conventions relating to the use of ICTs, one of which I will call "squatting". Although it is impossible to adequately develop and qualify this research's use of Strathern's notion of ownership and its theoretical influence on the the notion of "squatting", it is possible to briefly define "squatting" as the tactical use of institutional power in order to share and develop conventions relating to the use/consumption of ICTs in new media art.

\section{Conclusion}

Although it is certainly impossible to predict whether these artists' choices of technologies will one day lead to as successful an art world as photography, it is my hope that this research will at least lead to a greater appreciation of the dynamics of art world activity. The two principle objectives of this paper have been to present:

1) Conceptual tools for the study of organisational networks using ICTs, particularly how certain types of mediation of conventions, like ownership, might lead to a better understanding of the diffusion of creative practices and discourses relating to new media.

2) An introduction to the activities of the MARCEL Network and a wider understanding of artists' challenges and interests when working with ICTs. 


\section{References}

[1] Becker, H. S. (1982) Art Worlds, University of California Press, Berkeley and Los Angeles.

[2] de Certeau, M. (1984) The Practice of Everyday Life, University of California Press, Berkeley and Los Angeles.

[3] Foresta, D. and Barton, J. (1998) Leonardo, 31, 225-230.

[4] Kopytoff, I. (1986) In The Social Life of Things: Commodities in cultural perspective(Ed, Appadurai, A.) Cambridge University Press, Cambridge, pp. 64-91.

[5] Lammers, J. C. and Barbour, J. B. (2006) Communication Theory, 16, 356-377.

[6] Livingston, S. M. (1998) Making Sense of Television - The psychology of audience interpretation, Routledge, London.

[7] MARCEL Network (2004), About MARCEL (Ed, Foresta, D.) MARCEL Network, London. www.mmmarcel.org .

[8] Marcus, G. (1998) Ethnography Through Thick and Thin, Princeton University Press, Princeton, New Jersey.

[9] Martin-Barbero, J. (1993) Communication, Culture and Hegemony: From the media to mediations, Sage, London.

[10] Peterson, R. A. and Anand, N. (2004) Annual Review of Sociology, 30, 311-334.

[11] Phillips, N. (1993) Academy of Management Journal, 36, 1547-1576.

[12] Silverstone, R., Hirsch, E. and Morley, D. (1991) Cultural Studies, 5, 204-227.

[13] Strathern, M (1996) Social Anthropology, 4, 1, 17-32. 